\title{
Chloride accumulation in aboveground biomass of three macrophytes (Phragmites australis, Juncus maritimus, and Typha latifolia) depending on their growth stages and salinity exposure: application for $\mathrm{Cl}^{-}$removal and phytodesalinization
}

\author{
Emmanuel Delattre ${ }^{1} \cdot$ Isabelle Techer $^{1}$ (D) $\cdot$ Benjamin Reneaud $^{1} \cdot$ Patrick Verdoux $^{1} \cdot$ Isabelle Laffont-Schwob $^{2}$. \\ Philippe Prohin ${ }^{3}$
}

Received: 14 December 2020 / Accepted: 13 November 2021 / Published online: 20 January 2022

(c) The Author(s) 2022

\begin{abstract}
Anthropogenic activities can be the source of saline solid wastes that need to be treated to reduce their salt load to meet the purposes of reuse, valorization or storage. In this context, chloride remediation can be achieved using high-salt accumulating plants. However, there is very limited information on the comparative potential of different species in the same environment, and only scarce data concerning their efficiency as a function of growth stage. In order to rationalize these selection criteria, three macrophytes i.e., common reed (Phragmites australis), sea rush (Juncus maritimus), and cattail (Typha latifolia), were cultivated at two growth stages (6-months old and 1-year old) for 65 days in $\mathrm{Cl}^{-}$spiked substrates (from 0 up to $24 \%$ o $\mathrm{NaCl}$ ). The plants' survival and potential capacity for removal of $\mathrm{Cl}^{-}$from substrates and accumulation in shoots were investigated. For the three studied species, mature and juvenile plants display a high tolerance to salinity. However, mature specimens with higher shoot biomass and $\mathrm{Cl}^{-}$contents are capable of greater chloride removal than juvenile plants. The sole exception is $P$. australis which displays just the same phytoremediation potential for both mature and juvenile specimens. Moreover, $P$. australis has the lowest potential when compared with other species, being 1.5 and 3 times lower than for J. maritimus and T. latifolia. When considering the plant growth and the shoot biomass production, chloride removal rates from the substrate point that mature $J$. maritimus should preferentially be used to design an operational chloride remediation system. The results highlight the relevance of considering the growth stage of plants used for $\mathrm{Cl}^{-}$removal.
\end{abstract}

\section{Highlights}

1) Mature and juvenile specimens of J. maritimus, P. australis, and T. latifolia have high salinity tolerance in solid media spiked up to $24 \%$ o $\mathrm{NaCl}$.

2) Mature plants have generally better $\mathrm{Cl}^{-}$removal and phytoremediation performances than juvenile specimens.

3) J. maritimus is the most effective species for chloride phytoremediation with high survival and high $\mathrm{Cl}^{-}$sequestration in shoots.

4) T. latifolia has high $\mathrm{Cl}^{-}$removal in shoots and good remediation capacities but also shows sign of stress.

5) P. australis shows low $\mathrm{Cl}^{-}$sequestration and is a poor candidate for chloride remediation from substrate.

Keywords Salinity tolerance $\cdot$ Chloride bioaccumulation $\cdot$ Chloride removal $\cdot$ Phytodesalinization $\cdot$ Phytoremediation $\cdot$ Growth Stage $\cdot$ Common reed $\cdot$ Sea rush $\cdot$ Cattail

\section{Introduction}

Responsible Editor: Elena Maestri

Isabelle Techer

isabelle.techer@unimes.fr

Extended author information available on the last page of the article
Soil salinization represents a major environmental issue of our time. Being an extensive phenomenom which involves the accumulation of high concentrations of saline and sodic ions, soil salinization is expected to affect more than 830 
millions hectares of the continents (Daliakopoulos et al. 2016; Ivushkin et al. 2019). While salinization is known to be primarily caused by natural processes (primary salinization) that are accentuated by global climate changes, it can also be induced or enhanced by human activities, mainly irrigation (secondary salinization; Daliakopoulos et al. 2016). In a same way, many industrial processes (e.g., oil, paper and pulp industries, cement manufacturing, aquaculture, textile treatments, and application of road salts) can promote the salinity of natural ecosystems through the production of saline effluents (for review, see Litalien and Zeeb 2020). In addition, many anthropogenic activities generate saline solid wastes, including sediment and mud. For instance, harbour dredging is pointed out as a maintenance activity producing large amounts of saline sediments whose management is clearly challenging (Wang et al. 2018). This global context of salinization and the environmental issues raised have led to setting up of new regulations which promote the remediation of saline effluents, saline wastes and marine sediments, with the aim of protecting the environment. Among the ions involved in salinization, chloride is specifically targeted by these regulations, being considered harmful to ecosystems. For instance, chloride can make up more than $1 \%$ of the chemical composition of dredged sediments (Lim et al. 2020). The management of chloride-rich sediments and wastes is challenging as it is inconsistent with many industrial technologies classically used to treat and valorize these materials. High chloride contents are incompatible with most physical, thermal and chemical industrial remediation processes (leading to the degradation of the industrial facilities). Waste storage solutions are also drastically limited by the chloride concentrations (threshold on leachates set at $800 \mathrm{mg} \cdot \mathrm{kg}^{-1}$ for inert wastes, $15,000 \mathrm{mg}$. $\mathrm{kg}^{-1}$ for non-inert and non-hazardous wastes and $25,000 \mathrm{mg}$. $\mathrm{kg}^{-1}$ for hazardous wastes according to the French regulations). It would be of great interest to use high-salt accumulating plants to phytoremediate chloride-rich soils, effluents, and wastes since this passive treatment process has a low ecological and economic imprint (Jesus et al. 2015).

Salt phytoremediation can simply be defined as "the cultivation of salt accumulating or salt-tolerant plants for the reduction of [...] salinity and/or sodicity" (Qadir and Oster 2002). The phytoremediation of saline environments has thus a special character since it requires the use of plant species able to survive and adapt to saline ions in excess, and which can control saline ion concentrations through various mechanisms. Only halophytes species (i.e., about $1 \%$ of plant species, Flowers 2008) can be considered for this remediation purposes. Halophytes are salt tolerant species due to various adaptation mechanisms such as the exclusion of salt ions in excess at the root level, the uptake and sequestration of these ions in cells of the aerial organs (accumulator halophytes), or the ion excretion at leaf surfaces (recretohalophytes) (Yensen and Biel 2006). Most of the halophyte species studied for their ability to remediate saltaffected soils and effluents are accumulators (Brown et al. 1999; Doni et al. 2015; Jesus et al. 2014; Khandare and Govindwar 2015; Manousaki and Kalogerakis 2011; Masciandaro et al. 2014; Padmavathiamma et al. 2014; Pouladi et al. 2016; Qadir et al. 2007; Rabhi et al. 2009). These studies focus on the capacity of accumulators to sequester saline ions in the aboveground biomass. In recent years, some studies have dealt with the potential of recretohalophytes to remediate saline environments (Litalien and Zeeb 2020; McSorley et al. 2016a). Investigations are needed to validate the applicability of this last phenotype for depollution.

Hence, the most studied mechanism involved in the remediation of saline environments is the vacuolar sequestration of excess ions in the cells of the aerial parts of halophytes. Sequestration of excess cations, mainly $\mathrm{Na}^{+}$, is generally studied with respect to their toxicity for plants. In contrast, sequestration of $\mathrm{Cl}^{-}$anions is less well documented. Chloride is a micronutrient useful for plants, e.g. in photosynthesis, but can be phytotoxic at high levels (White and Broadley 2001). Some halophyte species are known for their capacity to accumulate chloride (Devi et al. 2016, 2008; Krishnapillai and Ranjan 2005; Rabhi et al. 2009, 2008; Hasanuzzaman et al. 2014). In this context, the most studied species are Atriplex spp., Avicennia spp., Phragmites spp., Salicorna spp., Sesuvium spp., Suaeda spp., Tetragonia spp., and Typha spp. For example, $\mathrm{Cl}^{-}$ion concentrations in shoots can reach $70 \mathrm{mg} . \mathrm{g}^{-1} \mathrm{DW}$ (dry weight) in Suaeda maritima (L.) Dumort., $20 \mathrm{mg} . \mathrm{g}^{-1} \mathrm{DW}$ in Aeluropus littoralis (Gouan) Parl. (Hasanuzzaman et al., 2014), 24 mg.g ${ }^{-1}$ DW in Phragmites australis (Cav.) Trin. ex Steud. (McSorley et al. 2016b), 20 mg. ${ }^{-1}$ in Juncus maritimus Lam. (Al Hassan et al. 2016) and range between $24 \mathrm{mg} \cdot \mathrm{g}^{-1}$ and up to $63 \mathrm{mg}$. $\mathrm{g}^{-1}$ in Typha latifolia $\mathrm{L}$. (Morteau et al. 2009; Rozema et al. 2014). By combining their high potential of $\mathrm{Cl}^{-}$accumulation and relatively high biomass, some halophytes can be used in phytoremediation to treat soils and effluents (Fountoulakis et al. 2017; Gorai et al. 2010; Guesdon et al. 2016; Jesus et al. 2015, 2017; McSorley et al. 2016b; Morteau et al. 2009; Calheiros et al. 2009, 2008; Rozema et al. 2014). However, little is known about how the age of a plant affects its aclimation to harmful saline media and its capacity to take up and store ions, and specifically chloride. In this framework, most of the studies deal only with the effect of salinity on seed germination (Boscaiu et al. 2011; Davy et al. 2006; Wu et al. 2016; Yu et al. 2012). To our knowledge, few authors gives any information on salt tolerance and $\mathrm{Cl}^{-}$ion sequestration as a function of plant growth stage (Chartzoulakis and Klapaki 2000; Zeng et al. 2002). Similarly, phytoremediation studies rarely report the growth stage at which plants are included in experiments. However, this criteria should be determinant in the choice of a phytoremediation 
model. For instance, Lissner and Schierup (1997) observed a higher mortality of juvenile plants of $P$. australis (10-weeks old) compared to larger rhizome-grown plants when cultivated in saline solutions. The challenge here is to define at which stage of growth specimens should be implanted in a system to be treated.

This study was performed in order to collect data on the tolerance of macrophyte species to $\mathrm{Cl}^{-}$-spiked substrates as well as on chloride accumulation and removal depending on their growth stage. The aim is to provide sufficient data to discuss the chloride removal potential of a given species as a function of growth stage at the time of its introduction into a saline matrix. Three macrophytes were selected as being tolerant to a large range of salinity and also because they are chloride accumulators used in soil and effluent remediation experiments: $P$. australis, J. maritimus, and T. latifolia. $P$. australis is a cosmopolitan glycophyte commonly used in wastewater treatment. Although it is not a true halophyte, it can tolerate environments with salinities up to $23 \%$ NaCl for haplotype $\mathrm{M}$ and $6 \%$ for others haplotypes (Vasquez et al. 2005). As mentioned above, it does not accumulate high contents of $\mathrm{Cl}^{-}$in its shoots, but compensates with a high aboveground biomass ( 1 to $5.5 \mathrm{~kg} . \mathrm{m}^{-2}$ ) (McSorley 2016a; Moore et al. 2012; Rozema et al. 2016). J. maritimus is less well documented, but is known to be tolerant to high salinities up to $30 \%$ NaCl (Boscaiu et al. 2011, 2007). In contrast, T. latifolia is mostly encountered in habitats with moderate salinity, between $12 \%$ and $24 \% \mathrm{NaCl}$ but with better salt removal capacity (Rozema et al. 2016, 2014).

While these three species are good candidates to remediate saline media, effluents or soils (Fountoulakis et al. 2017; Guesdon et al. 2016; Jesus et al. 2015, 2017; McSorley et al. 2016b; Morteau et al. 2009; Calheiros et al. 2009, 2008; Rozema et al. 2014; Prabakaran et al. 2019) it is difficult to determine which one is best suited for a given environment due to a lack of uniformity in the literature data where each species has often been studied separately under different experimental conditions. In this study, P. australis, J. maritimus and T. latifolia plants were cultivated at two growth stages in five distinct chloride concentrations in order to compare their ability to remediate saline environment and study the importance of the growing stage in this context.

\section{Materials and methods}

\section{Plants}

Seeds of Phragmites australis (Cav.) Trin. ex Steud. (Poaceae), Typha latifolia L. (Typhaceae) and Juncus maritimus Lam. (Juncaceae) were sown and the seedlings cultivated by an aquatic plant production company, Nymphea Distribution (France, Le Cailar, 30,740). Plants were harvested at two growth stages, 6 months and 1 year, as defined by their cultivation duration in the company greenhouses. These two sets of plants were called "juvenile" (j) and "mature" (m) respectively. The plants were collected along with their own substrate, composed of clays, black and white peat, as well as organic fertilizers such as dried poultry blood and guano (exact composition known but kept confidential for industrial reasons). The cultural practices of Nymphea Distribution are described in Delattre et al. (2020).

\section{Experimental conditions}

To compare between species and growth stages, the three studied macrophytes were introduced separately into plastic food containers, called microcosms. Due to the plant clod size, the container dimensions were of $12 \times 16 \times 10 \mathrm{~cm}$ for juvenile plants, and $20 \times 20 \times 10 \mathrm{~cm}$ for mature plants. For each species and each growth stage, four microcosms were observed being characterized by a given chloride enrichment. A given volume of 20 g. $\mathrm{L}^{-1} \mathrm{NaCl}$ solution was introduced to yield substrate chloride concentrations of $1,875 \mathrm{mg} \cdot \mathrm{kg}^{-1}$ (microcosm C1, 3\%o NaCl), 3,750 mg. $\mathrm{kg}^{-1}$ (microcosm C2, 6\% $\mathrm{NaCl}$ ), 7,500 mg. $\mathrm{kg}^{-1}$ (microcosm $\mathrm{C} 3,12 \% \circ \mathrm{NaCl}$ ) and $15,000 \mathrm{mg} \cdot \mathrm{kg}^{-1}$ (microcosm C4, 24\%。 $\mathrm{NaCl}$ ). These chloride contents from 1,875 up to $15,000 \mathrm{mg}$. $\mathrm{kg}^{-1}$, were selected as being close to critical threshold concentrations expected for waste storage according to French regulations. Microcosms were set up in triplicate for juvenile plants (12 plants/microcosm) and in duplicate for mature plants (9 plants/microcosm). For each set of juvenile and mature plants, a control microcosm was studied that was not enriched in $\mathrm{NaCl}(\mathrm{C} 0)$.

The cultivation was maintained under controlled environmental conditions in two cultivation rooms (Growbox@) for 80 days (between 27th April and 16th July, 2018) (Fig. 1). The dimension of these rooms did not allow the study of triplicates for mature plants. The two rooms communicated through a vent and were equipped with fans to homogenize the atmosphere and mimic wind effects on shoots (plant anemomorphosis). The photoperiod was set at $12 \mathrm{~h}$ with $400 \mathrm{~W}$ lamp HPI-T Plus (400 W/645 E40, PHILIPS), the hygrometry and temperature was monitored with a TESTO $175 \mathrm{H} 1$ probe (T: -20 to $+55 \pm 0.4{ }^{\circ} \mathrm{C}, \% \mathrm{RH}: 0$ to $100 \pm 2 \%$ ). The mean day temperature and hygrometry (between 6 a.m. and 6 p.m.) were respectively of $24.00 \pm 2.20^{\circ} \mathrm{C}(\max =29.2$, $\min =14.1)$ and $57.18 \pm 8.03 \%(\max =79.9, \min =31.0)$ while the mean night temperature and hygrometry (between 6 p.m. and 6 a.m.) were respectively of $21.39 \pm 2.25{ }^{\circ} \mathrm{C}$ $(\max =29.2, \min =14.0)$ and $63.90 \pm 9.98 \%(\max =80.6$, $\min =32.1$ ).

After $\mathrm{NaCl}$ enrichment, the plants were irrigated every two days to obtain a constant volume of $800 \mathrm{~mL}$ of water in each microcosm. The water used for irrigation was 


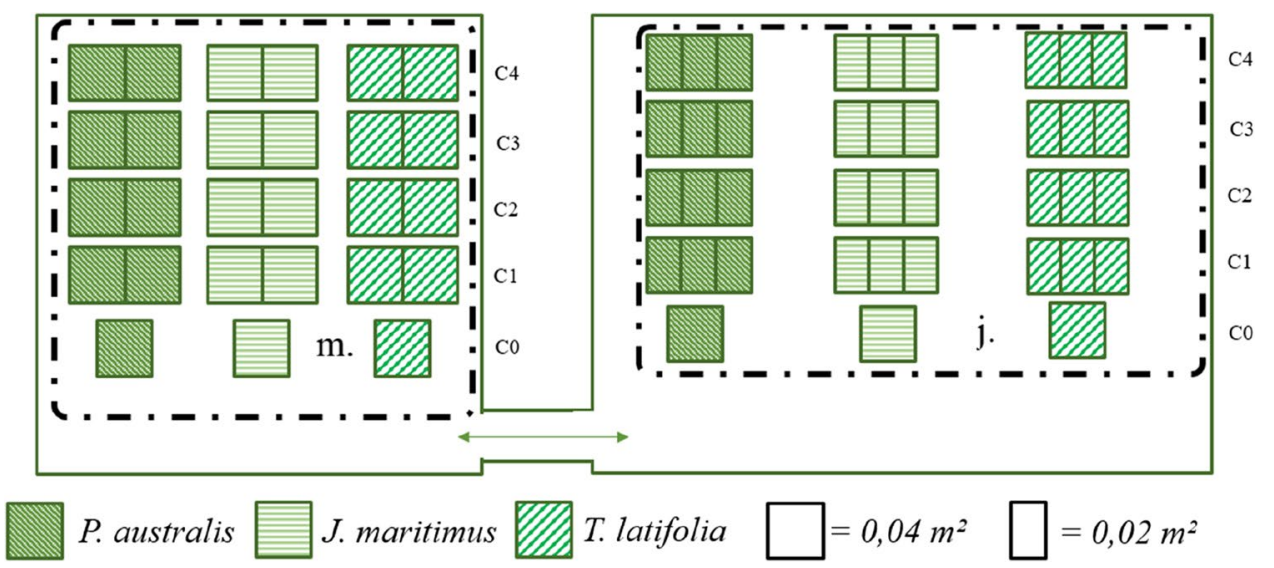

Fig. 1 Scheme of the cultivation rooms and disposition of the experimental microcosms. The arrow shows the air circulation. Microcosms are considered as a function of the substrate chloride contents in $\mathrm{mg} \cdot \mathrm{kg}^{-1} \mathrm{Cl}^{-}$and \%o $\mathrm{NaCl}(\mathrm{C} 0=0 ; \mathrm{Cl}=1,875 \mathrm{mg}$. $\mathrm{kg}^{-1}, 3 \%$; $\mathrm{C} 2=3,750 \mathrm{mg} \cdot \mathrm{kg}^{-1}, 6 \%$; $\mathrm{C} 3=7,500 \mathrm{mg} \cdot \mathrm{kg}^{-1}, 12 \%$; $\mathrm{C} 4=15,000 \mathrm{mg} \cdot \mathrm{kg}^{-1}, 24 \%$ ), the plants species (P. australis, J. maritimus and T. latifolia) and their growth ages $(\mathrm{m} .=$ mature plants, j.= juvenile plants) that initially introduced into the production system by the Nymphea Distribution company. This water was pumped from a local aquifer (groundwater from the Vistrenque aquifer) each week and stored in a $250 \mathrm{~L}$ container in HDPE for the purpose of the experiments. The chloride concentration of this irrigation water was determined over the course of the experiment and was of $62.7 \pm 0.5 \mathrm{mg} . \mathrm{L}^{-1}(2 \sigma, n=9)$. This result is in agreement with the value published by Sassine et al. (2015) for the Vistrenque groundwater. The volume of water added to the microcosms throughout the experiment led to a chloride "natural" flux input of approximately $1.3 \pm 0.4 \mathrm{~g}(1 \sigma)$ and $1.4 \pm 0.5 \mathrm{~g}(1 \sigma)$ for the $\mathrm{j}$ and $\mathrm{m}$ microscosms, respectively.

\section{Plant sampling}

Following the $\mathrm{NaCl}$ addition (t0), a first step of 2 weeks was adopted for plant aclimation. During this step, cultivation was maintained but no specimens were sampled. An initial shoot sampling was carried out before the adaptation period of 15 days (t0) and also afterwards (t0bis) to determine the initial $\mathrm{Cl}^{-}$shoot contents. Plants were then collected at day $3,9,15,25,36,45$, and 65 after aclimation periode (thereafter denoted as $\mathrm{t} 3, \mathrm{t} 9, \mathrm{t} 15, \mathrm{t} 25, \mathrm{t} 36, \mathrm{t} 45$, and $\mathrm{t} 65)$. The number of individuals sampled at each date was chosen to ensure sufficient biomass to allow measurements in triplicate. For the first three sampling dates, 2 plants were collected in each triplicate juvenile microcosms and 1 plant in the duplicate mature microcosms. For the following sampling dates, 1 plant was collected in each triplicate and duplicate microcosm for the juvenile and mature plants, respectively. At day 65 , the remaining plants were collected $(9$ specimens of juvenile plants; 2 specimens of mature plants). Only the aboveground biomass was sampled to study $\mathrm{Cl}^{-}$removal by phytoextraction simulating an industrial process that would take into account the growth of plants on the substrate to be treated and removal of the aerial parts, thus allowing new growth from resprouting. In such an industrial process, roots are not harvested to avoid replantation that would increase the operational expenditure.

\section{Plant sample treatment and analysis}

The shoots were cut and then dried at $75{ }^{\circ} \mathrm{C}$ for at least $48 \mathrm{~h}$. Fresh and dry mass was determined before and after drying to determine plant water contents. The biomass data are expressed in dry weight (DW) in the results section. Dried samples were then crushed with a ball mill (SPEX) and the powder sieved at $200 \mu \mathrm{m}$ (Pavlik 2000). The fine fraction was used to determine the chloride concentration in shoots by cold water extraction according to McSorley et al. (2016b). The chloride concentration of shoot extracted solutions was determined by silver titration. A solution of $0.01 \mathrm{M} \mathrm{AgNO}_{3}$ was prepared with a coloured indicator of $0.3 \mathrm{M}$ potassium chromate. A volume of extracted solution between 0.5 and $2 \mathrm{~mL}$ was introduced into a beaker and titrated to determine the chloride concentration with an electronic bottletop titrator. Chloride concentrations are expressed in $\mathrm{mg} \cdot \mathrm{g}^{-1} \mathrm{DW}$.

\section{Evaluation of survival rates}

The resistance and survival of species in each saline media were evaluated by counting the number of living and dead plants every two days during the experiment. Criteria for evaluating dead plants were senescence, lack of resprouting, 
stiffness and water content at touch (soaked when dead). The survival rate cannot be determined with classical methods because plant sampling in the microcosms over the duration of the experiment led to the occurrence of censored values. As a result, the survival rate was assessed with the Kaplan-Meier estimator ( $\hat{\mathrm{S}}(\mathrm{t})$ ) (Kaplan and Meier 1958) (Eq. 1).

$\widehat{S}(t)=\prod_{i: t_{i} \leq t}\left(1-d_{i} / n_{i}\right)$

With:

$t_{i}$, the time of observation,

$d_{i}$, the number of dead plants at the time $t_{i}$,

$\mathrm{n}_{\mathrm{i}}$, the number of plants known to survive (not included dead or censored).

\section{Total shoot $\mathrm{Cl}^{-}$contents}

To determine the total amount of chloride taken up by the plants in a given microscosm at the end of the experiment (in the 9 mature plants and 12 juvenile plants of the studied microcosms) (in $\mathrm{mg}$ of $\mathrm{Cl}^{-}$), the chloride contents (mg.g-1 DW) added at each time of sampling as well as the mass of aboveground collected shoots (g DW) were measured. The total chloride uptake is the sum of $\mathrm{Cl}^{-}$accumulated in each sample as expressed by the following equation:

$A C_{T}=\sum_{t i=0}^{65}\left(\left[\mathrm{Cl}^{-}\right]_{t i}-\left[\mathrm{Cl}^{-}\right]_{t-15}\right) \times m b_{t i}$

With:

$A C_{T}$, the total chloride amount accumulated in shoots of a given microscosm at the end of the experiment (in $\mathrm{mg}$ ), $\mathrm{mb}_{\mathrm{t}}$, the shoot biomass of the samples at time ' $\mathrm{i}$ ' ( $\mathrm{g} \mathrm{DW}$ ), $\left[\mathrm{Cl}^{-}\right]_{t i}$, the shoot $\mathrm{Cl}^{-}$concentration of the samples at time 'i' (mg.g $\left.{ }^{-1} \mathrm{DW}\right)$,

$\left[\mathrm{Cl}^{-}\right]_{t-15}$, the initial shoot $\mathrm{Cl}^{-}$concentration measured at time 't0bis' (mg.g $\left.{ }^{-1} \mathrm{DW}\right)$.

ti, time of sampling.

\section{Chloride removal from the substrate}

The chloride remediation of the substrate was determined by normalizing the total $\mathrm{Cl}^{-}$amount accumulated in the shoots to the total $\mathrm{Cl}^{-}$amount in the microcosm substrate at the beginning of the experiment. Taking into account $\mathrm{Cl}^{-}$inputs from the irrigation water, a removal ratio (expressed in \%) can be defined using Eq. 3 modified from McSorley et al. (2016b). As previously mentioned, this approach only accounts for chloride removal leading to accumulation in the shoots. Roots and rhizomes are not studied here as their harvest would not be required in an industrial production system.
$R=\frac{A C_{T}}{\left(\left[C l^{-}\right]_{m} \times m_{m}\right)+\left(\left[C l^{-}\right]_{w} \times V_{w}\right)}$

With:

$\mathrm{R}$, the shoot chloride removal rate in a given microcosm (in \%).

$A C_{T}$, the total shoot $\mathrm{Cl}^{-}$accumulation (in $\mathrm{mg}$ per microcosm),

$\left[\mathrm{Cl}^{-}\right]_{\mathrm{m}}$ the initial $\mathrm{Cl}^{-}$concentration in substrate of the microcosm $\left(\mathrm{mg} \cdot \mathrm{kg}^{-1}\right)$,

$\mathrm{m}_{\mathrm{m}}$ the mass of the substrate in the microcosm $(\mathrm{kg})$,

$\left[\mathrm{Cl}^{-}\right]_{\mathrm{w}}$ the $\mathrm{Cl}^{-}$concentration of the irrigation water (mg. $\left.\mathrm{L}^{-1}\right)$,

$\mathrm{V}_{\mathrm{w}}$ the volume of irrigation water added to the microcosm during the course of the experiment $(\mathrm{L})$.

The theoretical chloride removal $\left(\mathrm{R}_{\mathrm{t}}\right)$ can also be calculated assuming a scenario with no plant sampling over the experiment duration. This takes into account $n$ plants in each microcosm ( $n=9$ or 12$)$, by considering the biomass and shoot $\mathrm{Cl}^{-}$content measured at the end of the experiment (Eq. 4). In this scenario, the increase of biomass is assumed to be negligible, so the biomass measured at time $t_{i}$ can be taken as constant throughout the experiment; in fact, no significant growth of the plants was observed over the experiment duration (suppl. Information-Table 1).

$R_{t}=\frac{A C_{T} \text { Theo }}{\left(\left[\mathrm{Cl}^{-}\right]_{m} \times m_{m}\right)+\left(\left[\mathrm{Cl}^{-}\right]_{w} \times V_{w}\right)}$

The theoretical total shoot $\mathrm{Cl}$ - accumulation is calculated as follows:

$A C_{T}$ Theo $=\sum_{t i=0}^{65}\left(\left[\mathrm{Cl}^{-}\right]_{t 65}-\left[\mathrm{Cl}^{-}\right]_{t-15}\right) \times m b_{t i}$

With:

$\mathrm{Rt}$, the theoretical chloride removal rate in a given microcosm (in \%).

$A C_{T}$ Theo, the theoretical total shoot $\mathrm{Cl}^{-}$accumulation (in mg per microcosm) assuming that all the plants have the final $\mathrm{Cl}^{-}$concentration measured at $\mathrm{t} 65$,

$\left[\mathrm{Cl}^{-}\right]_{\mathrm{m}}$ the initial $\mathrm{Cl}^{-}$concentration in substrate of the microcosm $\left(\mathrm{mg} \cdot \mathrm{kg}^{-1}\right)$,

$\mathrm{m}_{\mathrm{m}}$ the mass of the substrate in the microcosm $(\mathrm{kg})$,

$\left[\mathrm{Cl}^{-}\right]_{\mathrm{w}}$ the $\mathrm{Cl}^{-}$concentration in the irrigation water $(\mathrm{mg}$. $\left.\mathrm{L}^{-1}\right)$,

$\mathrm{V}_{\mathrm{w}}$ the volume of irrigation water added into the microcosm throughout the experiment $(\mathrm{L})$.

\section{Statistical analysis}

All the analyses were carried out using R software (R Core Team 2018; RStudio Team 2016) (versions 3.5.1 and 1.1.456 respectively). Significant differences in survival rates were 
tested following the Neyman and Person approach $(p=0.05)$. Data were analysed with the survival package (Therneau and Grambsch 2000; Therneau 2015), and curves were plotted with the survminer package (Kassambara and Kosinski 2018). Multiple linear regressions were used to determine the impact of the cultivation duration, concentration and growth stage on the shoot water content and their $\mathrm{Cl}^{-}$concentration. Interactions between parameters and the final minimal adequate models were obtained by backward elimination of non-significant variables $(p<0.05)$. The normality of the residuals was checked prior to interpretation, while correlations between variables were tested with the Pearson's correlation test; both of these tests were taken from the stats package (R Core Team 2018). The multcompView package (Graves et al. 2015) was used to show significant distinction at $\mathrm{p}=0.05$ threshold on graphics developed with the ggplot2 package (Wickham 2016).

\section{Results}

\section{Survival rate}

Plant survival was monitored throughout the experiment. All the mature plants of the three macrophytes yied survival rates ranging between 88 and 100\% (Fig. 2; Supplementary Table 2). The mature plants of J. maritimus and $T$. latifolia show excellent survival rates of $100 \%$ whatever the salinity (from $\mathrm{C} 0$ to $\mathrm{C} 4$ ) whereas $P$. australis yield different results according to microcosms, with values of $100 \%$ for $\mathrm{C} 0, \mathrm{C} 3$ and $\mathrm{C} 4,92 \pm 8 \%$ for $\mathrm{C} 1$ and $88 \pm 12 \%$ for $\mathrm{C} 2$ (Fig. 2). Under similar conditions, juvenile plants show slightly higher mortality for $P$. australis and T. latifolia, but have the same survival rate (i.e., 100\%) as the mature plants of J. maritimus whatever the salinity. The juvenile $T$. latifolia plants display the lowest survival rates, with values of $60 \pm 22 \%$ for $\mathrm{C} 0,44 \pm 15 \%$ for $\mathrm{C} 1,45 \pm 13 \%$ for $\mathrm{C} 2$, $60 \pm 17 \%$ for $\mathrm{C} 3$ and $48 \pm 10 \%$ for C4. Intermediate survival rates are found for the juvenile plants of $P$. australis, i.e. $100 \%$ in both $\mathrm{C} 0$ and $\mathrm{C} 2$ microcosms and slightly lower in $\mathrm{C} 1, \mathrm{C} 3$ and $\mathrm{C} 4$, with values of $76 \pm 13 \%, 66 \pm 13 \pm$ and $85 \pm 8 \%$ respectively.

\section{Shoot water content}

Shoot water contents were evaluated at day $3,9,15,25,36$, 45 and 65. Similar values of shoot water contents in J. maritimus are measured whatever the cultivation duration and substrate chloride content for each growth stage considered separately (Fig. 3) (Table 1). However, significant differences are observed according to the plant growth stage: the average water content of the juvenile plants of J. maritimus is higher, ca. $71.3 \pm 5.1 \%(2 \sigma)$, compared with the mature plants, ca. $56.3 \pm 13.0 \%(2 \sigma)$. For $P$. australis, shoot water content also varies depending on the growth stage, with $48.1 \pm 14.7 \%(2 \sigma)$ at the juvenile stage and $58.2 \pm 14.6 \%$ $(2 \sigma)$ at the mature stage. For each salinity modality, a slight decrease of the shoot water content is observed over the experiment duration. However, due to measurements uncertainties this decrease cannot be considered as significant. Moreover, values are similar to those measured in the control microcosms ( $\mathrm{C} 0)$ at $\mathrm{t} 0$ and at the end of the experiment (t65). When considering water contents of the T. latifolia shoots, high variations are observed over time, with dependence on growth stages in all $\mathrm{Cl}^{-}$-spiked microcosms. Even at a same sampling time, a large variability is observed between the triplicate measurements. All microcosms combined, shoot water contents range from $26 \pm 12 \%$ to $91 \pm 14 \%$ without any clear tendency either among growth stages or among chloride spiked media (respective variances of 191 and 163 for juvenile and mature stages) (Fig. 3). In the control $\mathrm{C} 0$ microcosms, a constant water content is measured in shoots of mature T. latifolia over the experiment duration $(44 \pm 14 \%$ at t 0 ; $50 \pm 8 \%$ at 165$)$ whereas a clear decrease is observed in the juvenile specimens $(78 \pm 1 \%$ at $\mathrm{t} 0,40 \pm 19 \%$ at 655$)$.

\section{Shoot chloride contents}

Shoot chloride contents were evaluated at each sampling date. At the start of the experiment, the shoot $\mathrm{Cl}^{-}$contents of plants are low in the mature specimens of all three macrophytes $\left(9-10 \mathrm{mg} \cdot \mathrm{g}^{-1} \mathrm{DW}\right.$, mean values on triplicates), but can reach higher values in specimens considered at their juvenile stage, i.e., $20-25 \mathrm{mg} . \mathrm{g}^{-1}$ DW. Only juvenile $P$. australis specimens show low $\mathrm{Cl}^{-}$contents identical to the values found in mature plants. Chloride contents are inversely correlated with the plant biomass being lower in juvenile microcoms, except for $P$. australis which shows no significant variation in biomass between juvenile and mature specimens (Table 2 and supp data). Considering the evolution of $\mathrm{Cl}^{-}$contents over the experiment duration, two groups of plants can be distinguished: (i) plants whose shoots chloride contents remain stable or only increase slighty with time, values at 655 being 1 to at the most 3 times higher than those at t0 (i.e. juvenile and mature P. australis plants and juvenile J. maritimus plants). Maximum $\mathrm{Cl}^{-}$contents of $25-35 \mathrm{mg} \cdot \mathrm{g}^{-1}$ are measured in these plants at the end of the experiment. (ii) Plants characterized by shoot chloride contents that increase significantly over the experiment duration; at t65, these contents can reach values 4 to 10 times higher than initial contents (i.e. juvenile and mature T. latifolia plants and mature J. maritimus). Maximum $\mathrm{Cl}^{-}$contents of 100 to $120 \mathrm{mg} \cdot \mathrm{g}^{-1}$ are measured in T. latifolia, 
Fig. 2 A. Survival rates of the three studied species according to their growth stages (mature, m., juvenile, j.) and to the Cl-spiked substrate (in mg.kg ${ }^{-1} \mathrm{Cl}^{-}$and \%o $\mathrm{NaCl}$ : $\mathrm{C} 0=0 ; \mathrm{C} 1=1,875 \mathrm{mg} \cdot \mathrm{kg}^{-1}$, $3 \%$; $\mathrm{C} 2=3,750 \mathrm{mg} \cdot \mathrm{kg}^{-1}, 6 \%$; $\mathrm{C} 3=7,500 \mathrm{mg} \cdot \mathrm{kg}^{-1}, 12 \%$; $\mathrm{C} 4=15,000 \mathrm{mg} \cdot \mathrm{kg}^{-1}, 24 \%$ ). B. Zoom on the survival rates of juvenile specimens of $T$. latifolia with detailed graphic at each tested concentration. Rates are calculated based on the Kaplan Meier estimator. Confidence intervals are represented in dotted lines, cross marks correspond to censured data (sampled plants)
A

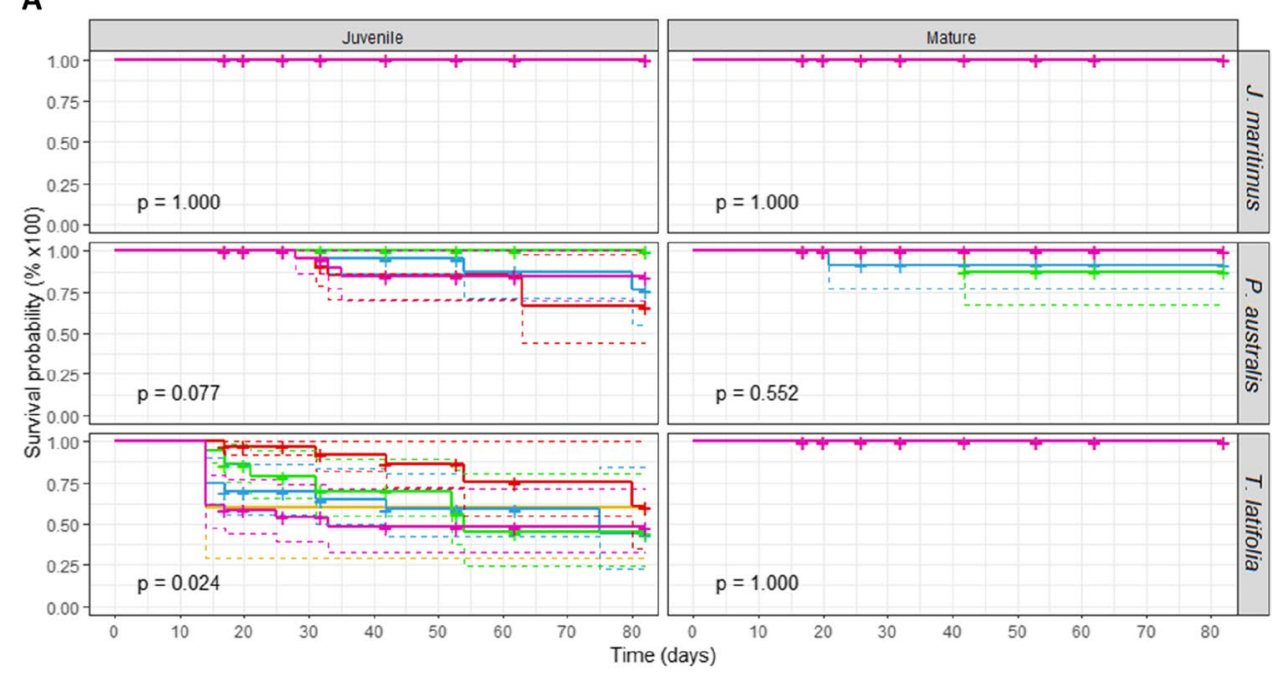

Concentration $+\mathrm{C}_{0}+\mathrm{C}_{1}+\mathrm{C}_{2}+\mathrm{C}_{3}+\mathrm{C}_{4}$

B
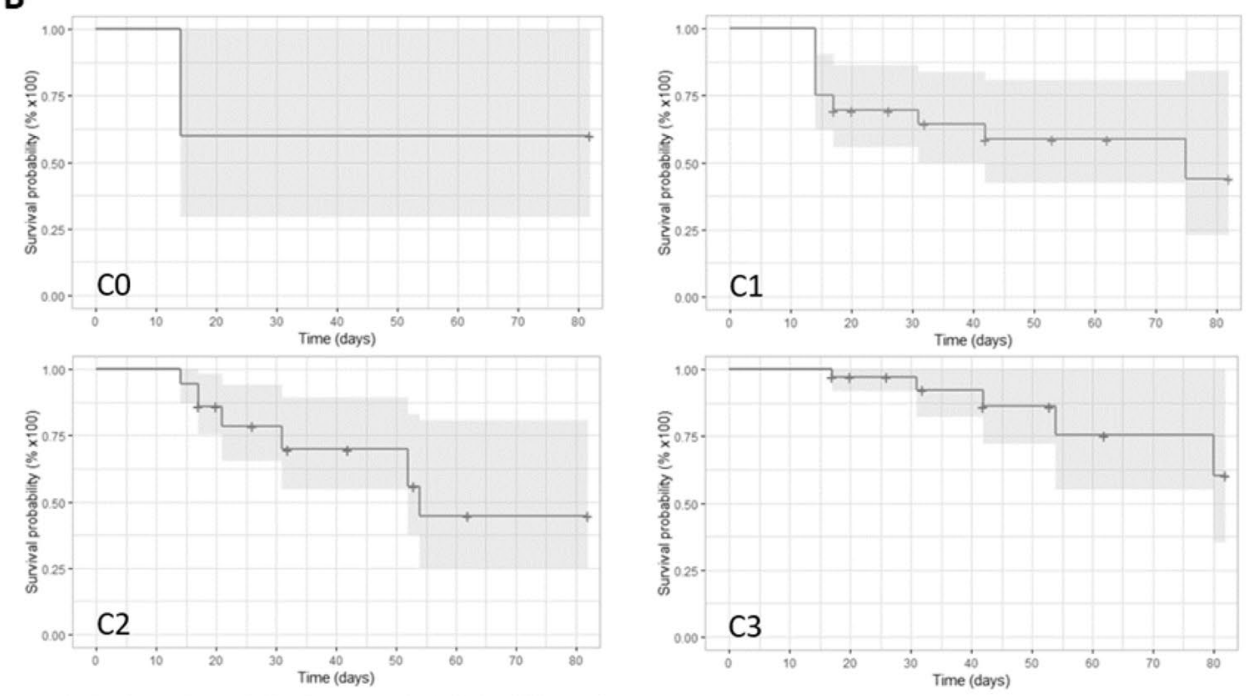

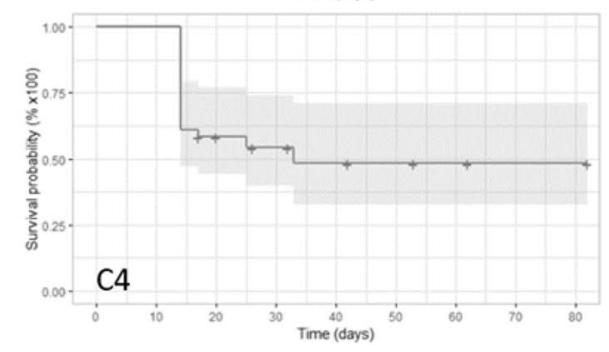

and of $84 \mathrm{mg} . \mathrm{g}^{-1}$ in J. maritimus. Mature J. maritimus plants show the greatest increase in $\mathrm{Cl}^{-}$shoot contents between t0 and t65 $(\times 10)$ (Fig. 4 and Table 2). Chloride shoot contents of macrophytes cultivated in $\mathrm{Cl}^{-}$-spiked microcosms are significantly higher than those measured in the control $\mathrm{C} 0$ microcosms (Table 2), except for juvenile $J$. maritimus that displays same $\mathrm{Cl}^{-}$accumulation in all microcosms whether saline or non-saline. In shoots of mature J. maritimus and juvenile P. australis, $\mathrm{Cl}^{-}$contents are significantly higher than the values obtained in the control microcosms (3 times higher). For juvenile and mature T. latifolia plants, the values obtained in shoots cultivated in the non-saline microcosms ( $\mathrm{C} 0)$ are surprisingly high and of the same order of magnitude as in spiked microcosms. 


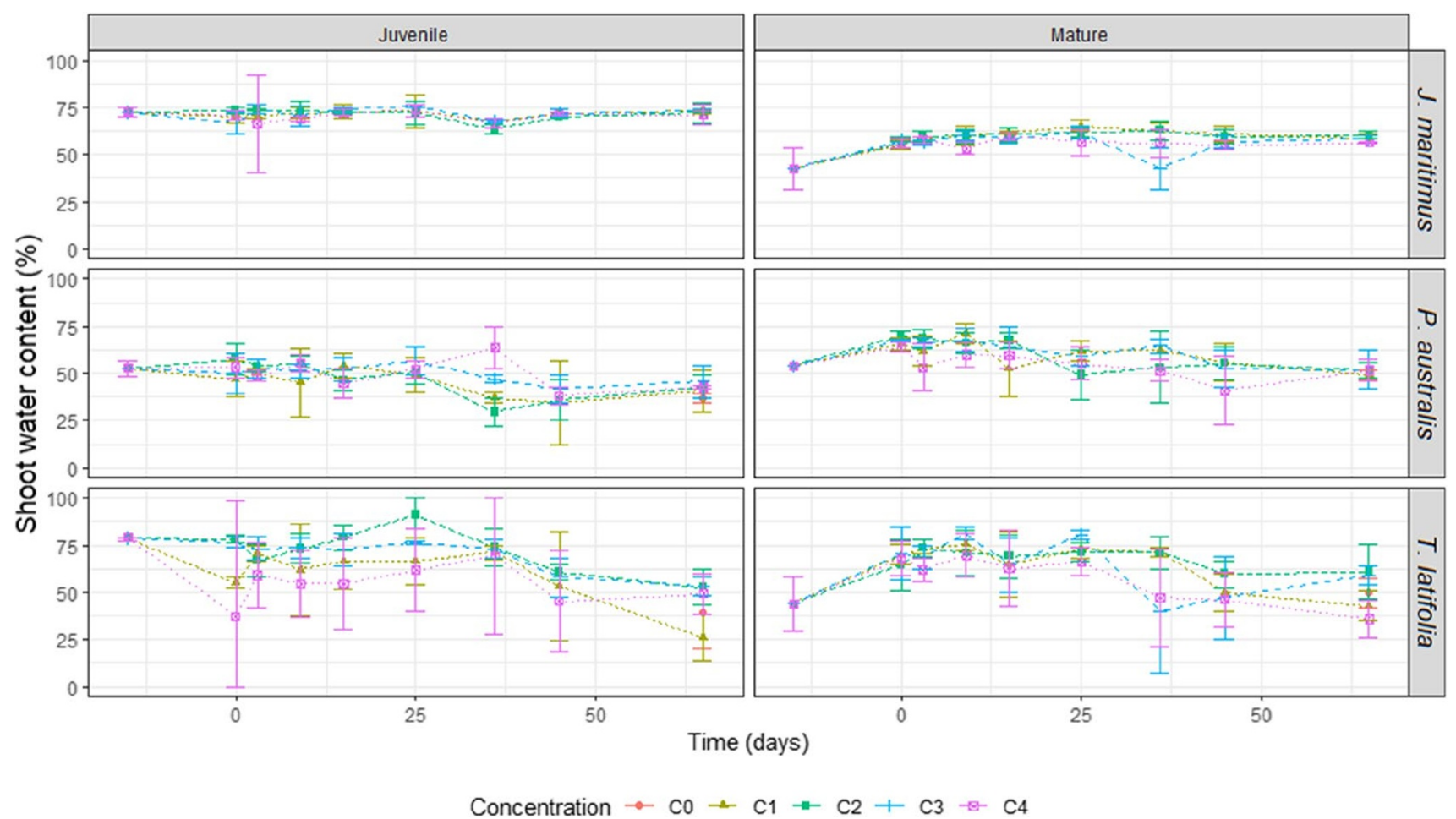

Fig. 3 Shoot water contents (\%) of the three studied species according to the growth stages (mature, m., juvenile, j.) in the different Cl-spiked microcosms (in mg. $\mathrm{kg}^{-1} \mathrm{Cl}^{-}$and \%o $\mathrm{NaCl}$ : $\mathrm{CO}=0$;

\section{Discussion}

\section{Tolerance to $\mathrm{Cl}^{-}$exposure}

Survival rates measured in the studied spiked-microcosms provide information on the salinity tolerance of the three macrophyte species as a function of their growth stage. Firstly, a comparison with the control microcosms allows to discriminate the intrinsic or extrinsic bias of the experiment. For instance all control microscoms show excellent survival rates except those of T. latifolia cultivated at its juvenile stage. This highlights the presence of other stresses than salinity that need to be considered in the following discussion. At their mature growth stage, individuals of the three macrophyte species do not show any signs of salinity stress up to $24 \% \circ \mathrm{NaCl}$ and $15,000 \mathrm{mg} \cdot \mathrm{kg}^{-1} \mathrm{Cl}^{-}$(Fig. 2). This is in agreement with literature on J. maritimus, which is described as being tolerant to high salinity; this species is documented to survive at least up to $30 \%$ NaCl (Boscaiu et al. 2011, 2007), the salinity condition of the studied C4 microcosm studied here. However, this is somewhat surprising for T. latifolia, which is a species mostly encountered in habitats with moderate salinity and known to be less resistant (Hootsmans and Wiegman 1998; Smith 1986; Jesus et al. 2014). In this study, mature T. latifolia plants grow perfectly
$\mathrm{C} 1=1,875 \mathrm{mg} \cdot \mathrm{kg}^{-1}, 3 \%$; $\mathrm{C} 2=3,750 \mathrm{mg} \cdot \mathrm{kg}^{-1}, 6 \%$; $\mathrm{C} 3=7,500 \mathrm{mg}$. $\mathrm{kg}^{-1}, 12 \%$; $\mathrm{C} 4=15,000 \mathrm{mg} \cdot \mathrm{kg}^{-1}, 24 \%$ ). Error bars represent variability among replicates

even at $24 \%$ NaCl. Although P. australis is known to be tolerant to a large range of salinity levels even with large variation at a local and at a regional scale due to the effets of climate and substrate clay content (Lissner and Schierup 1997; Lissner et al. 1999a, b; Mauchamp and Mésleard 2001; Burdick et al. 2001; Batriu et al. 2015; McSorley et al. 2016a, 2016b), this study shows that this species displays slightly lower survival rates at its mature stage. However, variations cannot be considered as significant when taking into account statistical parameters $(p>0.05)$. Moreover, the low survival rates are mainly observed in the low salt treatments ( $\mathrm{C} 1$ and $\mathrm{C} 2)$, which, according to the literature, are the most suitable conditions for the culture of this species, i.e., around $5 \%$ (Lissner and Schierup 1997; Hartzendorf and Rolletschek 2001). In contrast to mature plants, juvenile specimens of T. latifolia and P. australis show significantly lower survival rates. While the data cannot be interpreted as resulting from salinity stress for juvenile $T$. latifolia, they highlight a salinity stress for $P$. australis when immature. In the contrary, J. maritimus can adapt to $\mathrm{Cl}^{-}$exposure with a $100 \%$ survival rate whatever the plant growth stage (Fig. 2). These results may reflect physiological mechanisms that differ between facultative and obligate halophytes.

The water content of a plant is also an indicator of its tolerance to the growing environment (Matoh et al. 1988; 


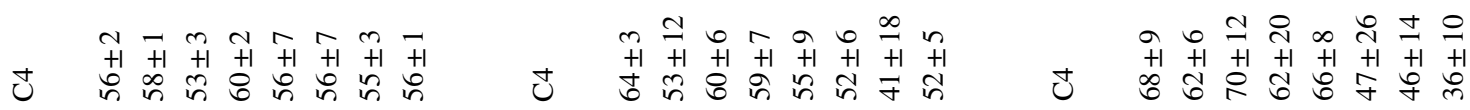

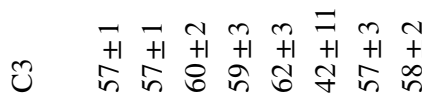

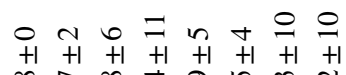

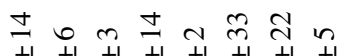

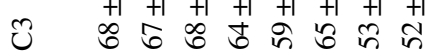

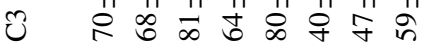

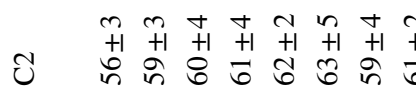

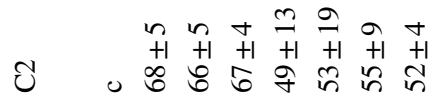

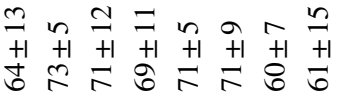

总

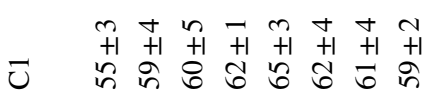

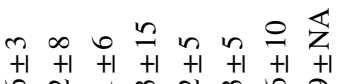

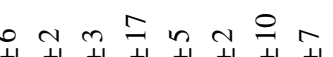

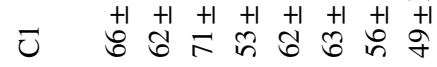

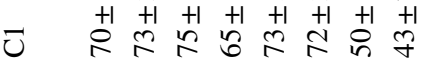

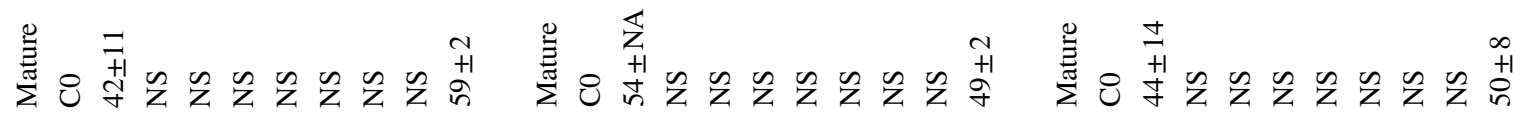

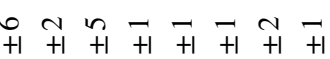

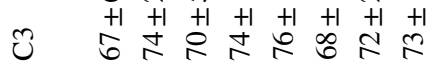

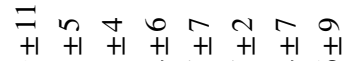

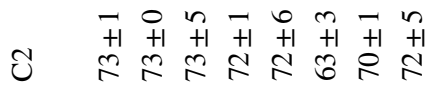

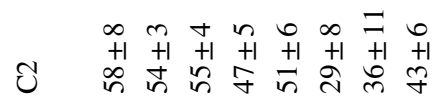

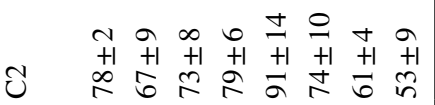


Table 2 Shoot chloride contents of the aboveground biomass collected at each sampling time. Values are expressed in $\mathrm{mg} \cdot \mathrm{g}^{-1} \mathrm{DW}$. Three replicates were sampled at each studied time; average values are given for the three replicates

\begin{tabular}{|c|c|c|c|c|c|}
\hline Time (days) & $\mathrm{CO}$ & $\mathrm{C} 1$ & $\mathrm{C} 2$ & $\mathrm{C} 3$ & $\mathrm{C} 4$ \\
\hline & \multicolumn{5}{|c|}{ J. maritimus Juvenile } \\
\hline-15 & \multirow[t]{8}{*}{25.1} & 25.1 & 25.1 & 25.1 & 25.1 \\
\hline 0 & & 21.8 & 24.2 & 23.2 & 25.7 \\
\hline 3 & & 25.1 & 25.0 & 26.9 & 26.3 \\
\hline 9 & & 21.5 & 25.3 & 24.7 & 25.5 \\
\hline 15 & & 22.6 & 23.3 & 27.5 & 30.3 \\
\hline 25 & & 21.6 & 22.9 & 25.2 & 28.2 \\
\hline 36 & & 24.9 & 25.3 & 34,0 & 37.4 \\
\hline 45 & & 27.0 & 31.7 & 33.1 & 37.2 \\
\hline 65 & \multirow[t]{2}{*}{33.6} & 28.7 & 36.1 & 39.5 & 37.6 \\
\hline 65: $\mathrm{Ci} / \mathrm{CO}$ & & 0.85 & 1.1 & 1.2 & 1.1 \\
\hline \multirow[t]{2}{*}{$R=t 65 / t 0$} & 1.3 & 1.1 & 1.4 & 1.6 & 1.5 \\
\hline & \multicolumn{5}{|c|}{ P. australis Juvenile } \\
\hline-15 & \multirow[t]{8}{*}{9.03} & 9.03 & 9.03 & 9.03 & 9.03 \\
\hline 0 & & 10.3 & 13.6 & 13.6 & 17.3 \\
\hline 3 & & 14.7 & 14.3 & 11.8 & 14.2 \\
\hline 9 & & 20.2 & 25,0 & 14.3 & 21.1 \\
\hline 15 & & 13.8 & 17.4 & 16.8 & 24.1 \\
\hline 25 & & 10.6 & 15.7 & 20.5 & 13.3 \\
\hline 36 & & 9.47 & 20.7 & 25.1 & 35.3 \\
\hline 45 & & 8.77 & 19.6 & 36.9 & 25.2 \\
\hline 65 & \multirow[t]{2}{*}{10.7} & 15.2 & 21.5 & 20.8 & 27.6 \\
\hline 65: $\mathrm{Ci} / \mathrm{CO}$ & & 1.4 & 2.0 & 1.9 & 2.6 \\
\hline \multirow[t]{2}{*}{$R=t 65 / t 0$} & 1.2 & 1.7 & 2.4 & 2.3 & 3.1 \\
\hline & \multicolumn{5}{|c|}{ T. latifolia Juvenile } \\
\hline-15 & \multirow[t]{8}{*}{21.1} & 21.1 & 21.1 & 21.1 & 21.1 \\
\hline 0 & & 41.0 & 35.3 & 46.6 & 53.3 \\
\hline 3 & & 41.1 & 52.5 & 70.4 & 59.7 \\
\hline 9 & & 58.3 & 52.8 & 49.2 & 77,0 \\
\hline 15 & & 40.7 & 46.5 & 45.6 & 61.2 \\
\hline 25 & & 37.9 & 55.8 & 65.1 & 72.3 \\
\hline 36 & & 59.8 & 63.6 & 94.7 & 85.8 \\
\hline 45 & & 43.6 & 91.1 & 66.9 & 137 \\
\hline 65 & \multirow[t]{2}{*}{83.8} & 88.1 & 85.6 & 84.7 & 127 \\
\hline 65: $\mathrm{Ci} / \mathrm{CO}$ & & 1.1 & 1.0 & 1.0 & 1.5 \\
\hline \multirow[t]{2}{*}{$R=t 65 / t 0$} & 4.0 & 4.2 & 4.1 & 4.0 & 6.0 \\
\hline & \multicolumn{5}{|c|}{ J. maritimus Mature } \\
\hline-15 & 8.6 & 8.6 & 8.6 & 8.6 & 8.6 \\
\hline 0 & & 26.6 & 32.1 & 29.4 & 46.2 \\
\hline 3 & & 28.6 & 23.6 & 40.4 & 44.3 \\
\hline 9 & & 29.5 & 35.3 & 31.3 & 65.5 \\
\hline 15 & & 31.1 & 38.3 & 38.1 & 63.3 \\
\hline 25 & & 26.8 & 29.6 & 44.3 & 42.1 \\
\hline 36 & & 33.2 & 41.5 & 61.2 & 80.9 \\
\hline 45 & & 22.6 & 30.6 & 32.8 & 98.7 \\
\hline 65 & 28.7 & 49.1 & 51.9 & 51.9 & 83.6 \\
\hline 65: $\mathrm{Ci} / \mathrm{CO}$ & & 1.7 & 1.8 & 1.8 & 2.9 \\
\hline
\end{tabular}

Table 2 (continued)

\begin{tabular}{|c|c|c|c|c|c|}
\hline Time (days) & $\mathrm{C} 0$ & $\mathrm{C} 1$ & $\mathrm{C} 2$ & $\mathrm{C} 3$ & $\mathrm{C} 4$ \\
\hline \multirow[t]{2}{*}{$R=t 65 / t 0$} & 3.4 & 5.7 & 6.1 & 6.1 & 9.8 \\
\hline & \multicolumn{5}{|c|}{ P. australis Mature } \\
\hline-15 & 10.7 & 10.7 & 10.7 & 10.7 & 10.7 \\
\hline 0 & & 15.2 & 16.8 & 15.5 & 22.5 \\
\hline 3 & & 13.6 & 14.7 & 15.9 & 14.3 \\
\hline 9 & & 16.7 & 15.4 & 18.3 & 37.3 \\
\hline 15 & & 16.0 & 17.5 & 16.4 & 29.9 \\
\hline 25 & & 16,0 & 15.2 & 17.3 & 19.0 \\
\hline 36 & & 17.2 & 21.6 & 17.6 & 18.3 \\
\hline 45 & & 21,0 & 18.8 & 21.0 & 39.9 \\
\hline 65 & 18.4 & 19.1 & 27.6 & 21.2 & 25.5 \\
\hline 65: $\mathrm{Ci} / \mathrm{CO}$ & & 1.0 & 1.5 & 1.1 & 1.4 \\
\hline \multirow[t]{2}{*}{$R=t 65 / t 0$} & 1.7 & 1.8 & 2.6 & 2.0 & 2.4 \\
\hline & \multicolumn{5}{|c|}{ T. latifolia Mature } \\
\hline-15 & 9.4 & 9.4 & 9.4 & 9.4 & 9.4 \\
\hline 0 & & 26.5 & 33.3 & 27.0 & 33.7 \\
\hline 3 & & 26.5 & 29.8 & 31.6 & 36,0 \\
\hline 9 & & 31.3 & 36.1 & 48.9 & 44.7 \\
\hline 15 & & 28.3 & 31.9 & 28.7 & 65.5 \\
\hline 25 & & 32.6 & 42.8 & 49.3 & 48.5 \\
\hline 36 & & 44.9 & 83.3 & 65.1 & 48.5 \\
\hline 45 & & 37.5 & 56.2 & 94.1 & 119 \\
\hline 65 & 39.1 & 55.5 & 52.8 & 119 & 65.2 \\
\hline 65: $\mathrm{Ci} / \mathrm{CO}$ & & 1.4 & 1.4 & 3.0 & 1.7 \\
\hline$R=t 65 / t 0$ & 4.1 & 5.9 & 5.6 & 12 & 6.9 \\
\hline
\end{tabular}

Lissner et al. 1999a, b). In combination with the survival data, the water content of the shoots is discussed here in relation to their tolerance to the saline media. Most of the measured values indicate a constant state of the shoot water content in the studied plants whatever the microscosms, salinity level or duration of cultivation, except for T. latifolia which shows a significant disturbed distribution as a function of time in a same microcosm (Fig. 3). Once again, the data show that the disturbance of the T. latifolia juvenile microcosms cannot be attributed to salinity alone since the $\mathrm{C} 0$ control systems behave the same. Except this system, all plants grow optimally in non-saline and in $\mathrm{Cl}^{-}$-spiked environments up to $15,000 \mathrm{mg} . \mathrm{g}^{-1}$. In the literature, a decrease of the shoot water content of $J$. maritimus and P. australis is reported for saline environments (Lissner et al. 1999a; Asaeda et al. 2003; Matoh et al. 1988). It is assumed to be related to an adaptation mechanism, with the purpose of reducing the osmotic potential while maintaining the turgor pressure (Turner and Jones 1980). 




Fig. 4 Shoot chloride contents (mg.g ${ }^{-1}$ DW) according to the growth stages (mature, m., juvenile, j.) in the different $\mathrm{Cl}$-spiked microcosms (in mg.kg ${ }^{-1} \mathrm{Cl}^{-}$and \%o $\mathrm{NaCl}$ : $\mathrm{C} 0=0 ; \mathrm{C} 1=1,875 \mathrm{mg}$. $\mathrm{kg}^{-1}, 3 \%$; $\mathrm{C} 2=3,750 \mathrm{mg} \cdot \mathrm{kg}^{-1}, 6 \%$; $\mathrm{C} 3=7,500 \mathrm{mg} \cdot \mathrm{kg}^{-1}, 12 \%$; $\mathrm{C} 4=15,000 \mathrm{mg} \cdot \mathrm{kg}^{-1}, 24 \%$ ). Error bars represent variability among replicates
Table 3 Coefficients of a multiple linear regression between the plant water content and the cultural duration (CD), the growth stage $(\mathrm{G})$, and the substrate chloride salinity in mg.g-1 (C) and their interactions. $n s$ non-significant, $*=p<0.05$, ** $=p<0.01$, and $* * *=p<0.001$. No-significant terms were withdrawn from the multiple linear regression calculation

\begin{tabular}{|c|c|c|c|}
\hline \multicolumn{4}{|l|}{ Shoot water contents } \\
\hline Variables & J. maritimus & T. latifolia & P. australis \\
\hline Intercept & $67.2 \pm 1.3 * * *$ & $80.8 \pm 5.7 * * *$ & $34.9 \pm 3.7 * * *$ \\
\hline Culture duration $(\mathrm{CD}) \% /$ day & ns & $-0.6 \pm 0.2 * *$ & $\begin{array}{l}-2.10^{-1} \pm 3 \cdot 10^{-2} \\
* * *\end{array}$ \\
\hline $\begin{array}{l}\mathrm{Cl} \text { salinity }(\mathrm{C}) \\
\% / \mathrm{mg} \cdot \mathrm{kg}^{-1}\end{array}$ & ns & ns & $9.10^{-4} \pm 4.10^{-4} *$ \\
\hline $\begin{array}{l}\text { Growth stage }(\mathrm{G}) \\
\text { Mathematical approach } \\
\% \text { / month }\end{array}$ & $-0.8 \pm 0.2 * * *$ & $-1.5 \pm 0.6 *$ & $2.4 \pm 0.4 * * *$ \\
\hline \multicolumn{4}{|l|}{ Interactions } \\
\hline $\begin{array}{l}\mathrm{CD}^{*} \mathrm{G} \\
\% \text { / day. month old }\end{array}$ & $8.10^{-3} \pm 4.10^{-3} *$ & $4.10^{-2} \pm 2.10^{-2} *$ & ns \\
\hline $\begin{array}{l}\mathrm{CD}^{*} \mathrm{C} \\
\% \text { / day. mg.kg }{ }^{-1}\end{array}$ & ns & ns & ns \\
\hline $\begin{array}{l}\mathrm{C}^{*} \mathrm{G} \\
\% / \mathrm{mg} \cdot \mathrm{kg}^{-1} \text {. month old }\end{array}$ & ns & ns & $-10.10^{-5} \pm 5.10^{-5} *$ \\
\hline $\begin{array}{l}\mathrm{CD}^{*} \mathrm{C}^{*} \mathrm{G} \\
\% \text { / day. } \mathrm{mg} \cdot \mathrm{kg}^{-1} \text {. month old }\end{array}$ & ns & ns & $\mathrm{ns}$ \\
\hline
\end{tabular}

To constrain the potential parameters affecting shoot water content, a multiple linear regression was performed using three variables: (i) cultivation duration, (ii) medium salinity, and (iii) plant growth stage (Table 3). This regression also helps analyse the interactions between the variables (Table 3). As a result, it can be observed that the water content of J. maritimus is not affected by the $\mathrm{Cl}^{-}$concentration of the growing substrate. Even with a $100 \%$ survival rate at its mature growth stage, $P$. australis shows some signs of weakening and is slightly 
affected by the salinity (slope $=9.10^{-4}, p<0.05$, and $\mathrm{C}^{*} \mathrm{G}$ slope $\left.=-10.10^{-5}, p<0.05\right)$ (Table 3$)$. For this species, an adaptation mechanism by water content control can be proposed. For T. latifolia, no significant relation exists between the substrate $\mathrm{Cl}^{-}$concentration and its water content (or its survival rate). The behaviour of this species is not exclusively linked to the $\mathrm{Cl}^{-}$exposure as outlined above. The multiple linear regression also highlights a relationship between the shoot water content and plant growth stage for J. maritimus and $P$. australis (also observed in Fig. 3). Based on the elapsed time of pre-culture (taking a numerical value of ' 6 ' for juvenile -6 months, and ' 12 ' for mature -1 year), a slope of $-0.8 \pm 0.2 \% /$ month old $(p<0.001)$ and of $2.4 \pm 0.4 \%$ / month $(p<0.001)$ can be measured for J. maritimus and $P$. australis respectively. The cultivation duration would appear to influence the $P$. australis water content (slope $=-0.16 \pm 0.03 \% /$ day, $p<0.001$ ) while it has no effect on the J. maritimus. In summary, the multiple linear regression method confirms that the shoot water contents of J. maritimus and P. australis depend on the age of plant in all treatments, whereas no systematic relation exists regarding the media $\mathrm{Cl}^{-}$concentration. The shoot water contents of T. latifolia is not linked with the three variables studied here: $\mathrm{Cl}^{-}$exposure level, plant age, and cultivation duration. The behaviour of this species needs to be explained by at least some parameter other than salinity.

\section{Shoots chloride accumulation}

For the three macrophytes, a slight increase of the shoot $\mathrm{Cl}^{-}$concentration is observed in the control microcosms (C0) from t0 to t65 ( $t$ test, $p<0.001$ ). This increase is assigned to the $\mathrm{Cl}^{-}$supplied to the microcosms due to irrigation with water containing $62.7 \pm 0.5 \mathrm{mg} . \mathrm{L}^{-1} \mathrm{Cl}^{-}$(Supplementary Table 3).

At day 65, only mature specimens of J. maritimus and juvenile individuals of $P$. australis have shoot $\mathrm{Cl}^{-}$contents significantly higher in $\mathrm{Cl}^{-}$-spiked microcosms than in the controls ( $\mathrm{C} 0)$. This highlights a mechanism of uptake, translocation and sequestration of the $\mathrm{Cl}^{-}$ions in shoots that is specific to both species for the considered growth stage. By contrast, neither J. maritimus at its juvenile stage nor $P$. australis at its mature stage demonstrate a high $\mathrm{Cl}^{-}$sequestration potential, since their shoot $\mathrm{Cl}^{-}$contents are close to those measured in the control microcosm. The behaviour of these plants is governed by a mechanism of chloride exclusion by roots, pointing out the importance of variations in plant metabolism as a function of plant growth stage. Although it would be interesting to investigate the metabolic mechanisms in more detail, the purpose of this study remains focused on evaluating the impact of these phenomena on the desalinization potential of the selected species. T. latifolia shows a high capacity of $\mathrm{Cl}^{-}$sequestration that is surprisingly also demonstrated in non-saline media (control C0 microcosms). It is as if the plant is able to take up chloride ions, not only those added to the system but also those intimately linked to the mineral substrate. $P$. australis is a $\mathrm{Cl}^{-}$accumulator species, with juvenile plants being able to accumulate chloride in their aerials parts up to a maximum critical threshold value of around $25 \mathrm{mg} \cdot \mathrm{g}^{-1}$ DW. This is in agreement with the values of $24 \mathrm{mg} \cdot \mathrm{g}^{-1} \mathrm{DW}$ reported in literature (McSorley et al. 2016b). J. maritimus is also documented as exhibiting shoot chloride accumulation at levels of ca. $20 \mathrm{mg} . \mathrm{g}^{-1}$ DW (Al Hassan et al. 2016); such levels are indeed measured in our experiments with juvenile plants. However, mature specimens of $J$. maritimus are found to be better accumulators than juveniles, with shoots $\mathrm{Cl}^{-}$contents of around $85-90 \mathrm{mg} . \mathrm{g}^{-1} \mathrm{DW}$. Compared to the two other macrophytes, both juvenile and mature $T$. latifolia plants show higher chloride accumulation than expected from literature, with reported values of 24-63 mg. $\mathrm{g}^{-1} \mathrm{Cl}^{-}$DW (Morteau et al. 2009; Rozema et al. 2014). To our knowledge, the present study is the first report of such high values of $\mathrm{Cl}^{-}$in $T$. latifolia shoots, reaching levels of ca. $100-120 \mathrm{mg} \cdot \mathrm{g}^{-1} \mathrm{DW}$.

\section{Chloride removal and phytoremediation capacity}

The phytoremediation potential of the studied plants and mainly those identified as chloride accumulators can be assessed by taking into account not only shoot $\mathrm{Cl}^{-}$contents in mg.g $\mathrm{g}^{-1} \mathrm{DW}$ but also the effective biomass of the species. By considering the 12 to 9 individuals making up the studied microcosms, $\mathrm{Cl}^{-}$removal rates can be expressed in terms of the proportion (\%) of chloride ions in the substrate removed by the harvested shoots, as determined according to Eqs. 3, 4, and 5 (Fig. 5). In all treatments, the removal rate is inversely correlated with the $\mathrm{Cl}^{-}$amount in the substrate, decreasing when the substrate $\mathrm{Cl}^{-}$contamination increases. However, while the salinity increases by a factor of 2 (from $\mathrm{C} 0$ to $\mathrm{C} 4$ ), the removal is only reduced of a few percents. Hence, the greater the $\mathrm{Cl}^{-}$contamination of the substrate, the higher the phytoextraction. The removal rate ranges from a few percent in the $P$. australis microcosms and can reach $20-25 \%$ in the mature J. maritimus and T. latifolia microcosms (Fig. 5). As mentioned previously, neither the mature and juvenile $P$. australis plants, nor the juvenile $J$. maritimus, are able to remediate efficiently the salinity of their substrate whatever the $\mathrm{Cl}^{-}$-spiked conditions (rate $<10 \%$ ). Mature individuals of $J$. maritimus and T. latifolia are the most suitable species for a phytodesalinization process. This result is of interest as J. maritimus is less often studied in phytoremediation processes as it is known to produce low 
Fig. 5 Chloride removal rates from substrates spiked from $1,875 \mathrm{mg} \cdot \mathrm{kg}^{-1}(\mathrm{C} 1)$ to $15,000 \mathrm{mg} \cdot \mathrm{kg}^{-1}$ in $\mathrm{Cl}^{-}(\mathrm{C} 4)$ : capacity of removal in \% of the three studied macrophytes tested at different growth stages (bar $=$ average \pm SE, $n=3$, point $=$ individual value). Full bars with white circles correspond to values achieved with sampled plants while shaded dotted bars with cross represent theoretical values calculated in a scenario with no plants sampling over the experiment duration. $\mathrm{Cl}=3 \%$ NaCl; $\mathrm{C} 2=6 \% \circ \mathrm{NaCl} ; \mathrm{C} 3=12 \%$ 。 $\mathrm{NaCl} ; \mathrm{C} 4=24 \%$ o $\mathrm{NaCl}$. Letters are used to show significant difference between mean value with Student t-test at a threshold of $p=0.05$

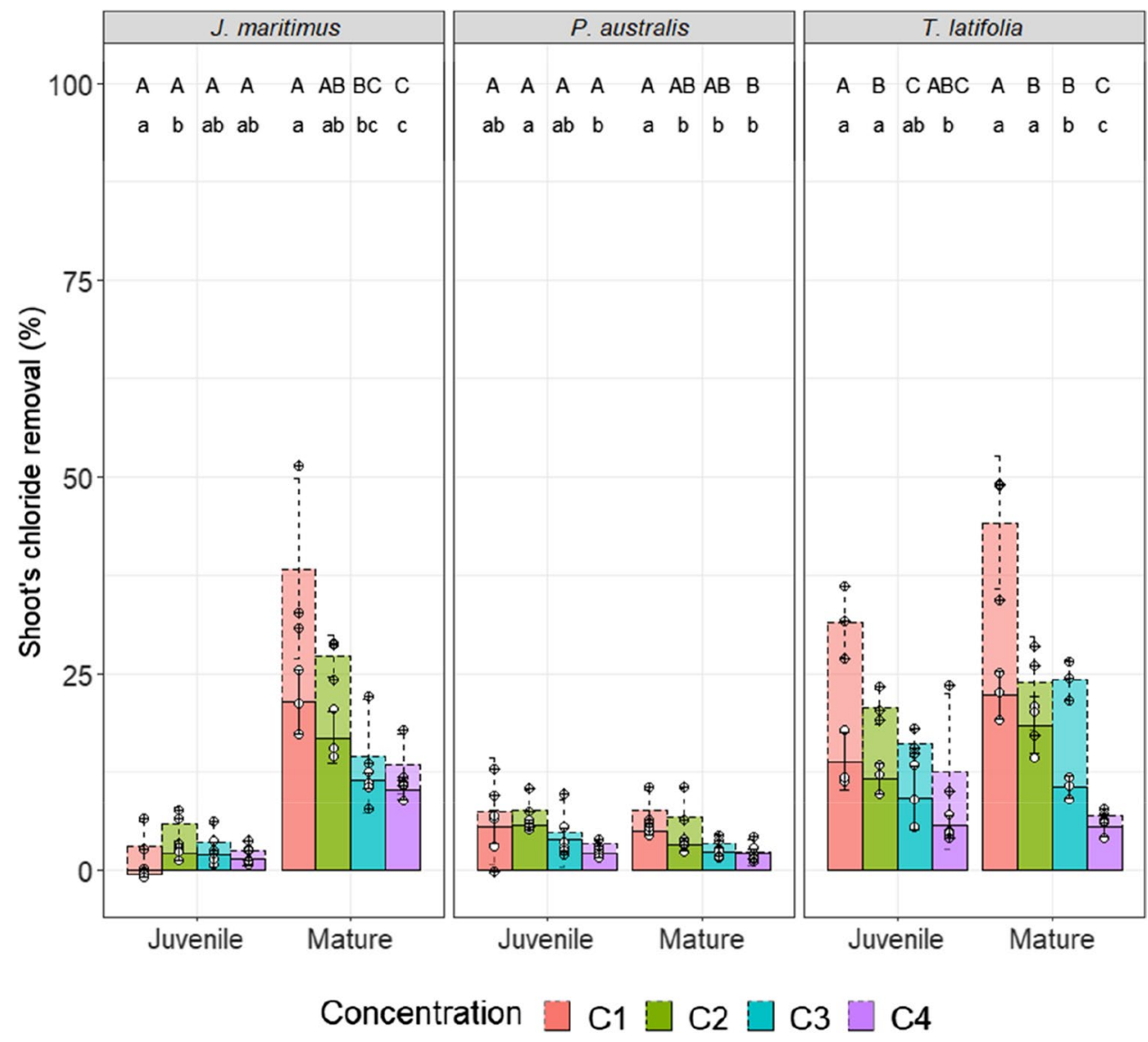

biomass (less than $1 \mathrm{~kg} \cdot \mathrm{m}^{-2} \cdot \mathrm{y}^{-1}$ ) compared to P. australis and T. latifolia (between $1 \mathrm{~kg} \cdot \mathrm{m}^{-2} \cdot \mathrm{y}^{-1}$ and $5.5 \mathrm{~kg} \cdot \mathrm{m}^{-2} \cdot \mathrm{y}^{-1}$ ) (Coon et al. 2000; Ennabili et al. 1998; Ennabili and Ater 2005; Rozema et al. 2016; Guesdon et al. 2016; McSorley et al. 2016b).

However, in the present study, chloride removal rates were determined in microcosms in which plants were sampled over time. As a result, the removal rates are underestimated. They would have been higher if no plants had been removed from the microcosms. To draw up a scenario with no plant sampling over 65 days (closer to a realistic scenario of phytoremediation), "theoretical" removal rates were calculated, assuming that all the biomass of a given microcosm have the shoot $\mathrm{Cl}^{-}$contents measured in samples at day 65. Figure 5 reports these theoretical removal rates (\%) as a shaded doted bar. Compared to those previously discussed, the same trends are observed according to plant species and $\mathrm{Cl}^{-}$exposure. However, the $\mathrm{Cl}^{-}$fraction phytoextracted from the substrate is almost doubled and can reach $50 \%$ when considering mature J. maritimus and T. latifolia. $\mathrm{Net}^{-}$removal rates would be substantially higher by assuming that a full-scale phytoremediation process would be dimensioned with plants cultivated over a duration of several months to a year with a harvest once a year. In this way, we can demonstrate the effectiveness of the phytoremediation of the $\mathrm{Cl}^{-}$-spiked substrate for mature J. maritimus and T. latifolia plants. $\mathrm{Cl}^{-}$accumulation in roots was not investigated in this study. However, $P$. communis is known to have high root $\mathrm{Cl}^{-}$concentrations (Matoh et al. 1988) suggesting that the substrate remediation could be also achieved by combining the shoot $\mathrm{Cl}^{-}$removal (this study) with $\mathrm{Cl}^{-}$sequestration in roots. Moreover, root growth is less disturbed by the salinity than is the case for the aerial plant parts (Adam 1990; Cheeseman 1988). It would be interesting to determine the $\mathrm{Cl}^{-}$amounts accumulated in the roots of the studied macrophytes to assess their global capacity to remediate $\mathrm{Cl}^{-}$enriched media.

\section{Conclusion}

Oldest (mature) plants of all three selected species are shown to have the higher survival rates, underlying the need to take into account the growth stage of plants when dealing with $\mathrm{Cl}^{-}$phytoremediation. $P$. australis shows a specific range of salinity resistance, being well adapted to medium saline 
environments with a low chloride phytoextraction potential at both growth stage. By contrast, the potential for chloride extraction and translocation into aerial parts of J. maritimus and T. latifolia is demonstrated. For J. maritimus, this innovative result implies that the efficiency of the phytoextraction mechanism varies as a function of the plant growth stage with the oldest specimens having higher accumulation and removal capacities. Taken together, the combined data lead us to a realistic evaluation of chloride removal and indicate that $J$. maritimus followed by T. latifolia seem to be the best adapted species to remediate chloride salinity from soils or wastes.

Supplementary Information The online version contains supplementary material available at https://doi.org/10.1007/s11356-021-17591-3.

Acknowledgements This study was conducted within a collaboration between Nymphea Distribution and Nîmes University in the framework of a PhD supported by Nîmes Metropole. The authors are most grateful to the Nymphea Distribution team for the valuable information on macrophyte production and culture as well as for providing plants and access to its site. The authors are also very grateful to the two reviewers whose remarks and suggestions helped to improve the work and to Michael Carpenter who improved the English style and grammar. This research program did not benefit from any specific grants from the usual funding agencies in the public, commercial or not-for-profit sectors.

Author contribution E. Delattre: defined the protocol, conducted the experiment, analysed and interpreted the data, and was a major contributor to writing the manuscript.

I. Techer: defined the protocol and interpreted the data, and was a major contributor to writing the manuscript.

B. Reneaud: performed the sampling and chemical analyses.

P. Verdoux: assisted in the setting up and tracking of the experiment, and 47 also supervised the analytical plateform.

P. Prohin: produced the studied macrophytes, supplied water samples and contributed to the discussion and interpretation.

I. Laffont-Schwob: contributed to the discussion and strenghthened the biological interpretations and citations.

All authors read and approved the final manuscript.

Data availability All data generated or analyzed during this study are included in the published article and supplementary information files. More information is available from the corresponding author on reasonable request.

\section{Declarations}

Ethics approval and consent to participate Not applicable.

Consent for publication Not applicable.

Competing interests The authors declare no competing interests.

Open Access This article is licensed under a Creative Commons Attribution 4.0 International License, which permits use, sharing, adaptation, distribution and reproduction in any medium or format, as long as you give appropriate credit to the original author(s) and the source, provide a link to the Creative Commons licence, and indicate if changes were made. The images or other third party material in this article are included in the article's Creative Commons licence, unless indicated otherwise in a credit line to the material. If material is not included in the article's Creative Commons licence and your intended use is not permitted by statutory regulation or exceeds the permitted use, you will need to obtain permission directly from the copyright holder. To view a copy of this licence, visit http://creativecommons.org/licenses/by/4.0/.

\section{References}

Adam P (1990) Coping with the environment, in: Saltmarsh Ecology, Cambridge Studies in Ecology. Cambridge University Press, pp. 207-308. https://doi.org/10.1017/CBO9780511565328.005

Al Hassan M, López-Gresa M del P, Boscaiu M, Vicente O (2016) Stress tolerance mechanisms in Juncus: responses to salinity and drought in three Juncus species adapted to different natural environments. Funct Plant Biol 43:949. https://doi.org/10.1071/ FP16007

Asaeda T, Manatunge J, Fujino T, Sovira D (2003) Effects of salinity and cutting on the development of Phragmites australis. Wetl Ecol Manag 11:127-140. https://doi.org/10.1023/A:1024289025415

Batriu E, Ninot JM, Pino J (2015) Interactions between transplants of Phragmites australis and Juncus acutus in mediterranean coastal marshes: the modulating role of environmental gradients. Aquat Bot 124:29-38. https://doi.org/10.1016/j.aquabot.2015.03.003

Boscaiu M, Ballesteros G, Naranjo A, Vicente O (2011) Responses to salt stress in Juncus acutus and J maritimus during seed germination and vegetative plant growth. Plant Biosyst 145(4):770-777

Boscaiu M, Ballesteros G, Naranjo MA, Vicente O, Boira H (2007) Responses of halophytes to salt stress. Bul. USAMV-CN 1454-2382

Brown JJ, Glenn EP, Fitzsimmons KM, Smith SE (1999) Halophytes for the treatment of saline aquaculture effluent. Aquaculture 175:255-268

Burdick DM, Buchsbaum R, Holt E (2001) Variation in soil salinity associated with expansion of Phragmites australis in salt marshes. Environ Exp Bot 46:247-261. https://doi.org/10.1016/S00988472(01)00099-5

Calheiros CSC, Rangel AOSS, Castro PML (2009) Treatment of industrial wastewater with two-stage constructed wetlands planted with Typha latifolia and Phragmites australis. Bioresour Technol 100:3205-3213. https://doi.org/10.1016/j.biortech.2009.02.017

Calheiros CSC, Rangel AOSS, Castro PML (2008) Evaluation of different substrates to support the growth of Typha latifolia in constructed wetlands treating tannery wastewater over long-term operation. Bioresour Technol 99:6866-6877. https://doi.org/10. 1016/j.biortech.2008.01.043

Chartzoulakis K, Klapaki G (2000) Response of two greenhouse pepper hybrids to $\mathrm{NaCl}$ salinity during different growth stages. Sci Hortic 86:247-260. https://doi.org/10.1016/S0304-4238(00)00151-5

Cheeseman JM (1988) Mechanisms of salinity tolerance in Plants. Plant Physiol 87:547-550

Coon WF, Bernard JM, Seischab FK (2000) Effects of a cattail wetland on water quality of Irondequoit Creek near Rochester, New York, US Geologi. ed

Daliakopoulos IN, Tsanis IK, Koutroulis A, Kourgialas NN, Varouchakis AE, Karatzas GP, Ritsema CJ (2016) The threat of soil salinity: an European scale review. Sci Total Environ 573:727-739. https://doi.org/10.1016/j.scitotenv.2016.08.177

Davy AJ, Bishop GF, Mossman H, Redondo-Gómez S (2006) Biological flora of the British isles: Sarcocornia perennis (Miller) A.J. Scott. J Ecol 14 
Delattre E, Techer I, Reneaud B, Thireau V, Verdoux P, Prohin P (2020) $\mathrm{Sr}$ isotope discrimination of multi species aquaculture productions at a worldwide scale and contribution of the water reservoir in $\mathrm{Sr}$ plant input. Heliyon 6:e03075. https://doi.org/10.1016/j.heliyon. 2019.e03075

Devi S, Nandwal AS, Angrish R, Arya SS, Kumar N, Sharma SK (2016) Phytoremediation potential of some halophytic species for soil salinity. Int J Phytoremediation 18:693-696. https://doi.org/ 10.1080/15226514.2015.1131229

Devi S, Rani C, Datta KS, Bishnoi SK, Mahala SC, Angrish R (2008) Phytoremediation of soil salinity using salt hyperaccumulator plants. Indian J Plant Physiol 13:347-356

Doni S, Macci C, Peruzzi E, Iannelli R, Masciandaro G (2015) Heavy metal distribution in a sediment phytoremediation system at pilot scale. Ecol Eng 81:146-157

Ennabili A, Ater M (2005) Diversité floristique et production de biomasse des macrophytes des marais de Smir. Trav Inst Sci Sér Générale 4:17-25

Ennabili A, Ater M, Radoux M (1998) Biomass production and NPK retention in macrophytes from wetlands of the Tingitan Peninsula. Aquat Bot 62:45-56

Flowers TJ (2008) Salinity tolerance in halophytes. New Phytol 179:945-963

Fountoulakis MS, Sabathianakis G, Kritsotakis I, Kabourakis EM, Manios T (2017) Halophytes as vertical-flow constructed wetland vegetation for domestic wastewater treatment. Sci Total Environ 583:432-439. https://doi.org/10.1016/j.scitotenv.2017. 01.090

Gorai M, Ennajeh M, Khemira H, Neffati M (2010) Combined effect of NaCl-salinity and hypoxia on growth, photosynthesis, water relations and solute accumulation in Phragmites australis plants. Flora - Morphol. Distrib Funct Ecol Plants 205:462-470. https:// doi.org/10.1016/j.flora.2009.12.021

Graves S, Piepho H-P, with help from Sundar Dorai-Raj LS (2015) multcompview: visualizations of paired comparisons

Guesdon, De Santiago-Martin A, Galvez-Cloutier R (2016) Phytodesalinization potentiel of Typha angustifolia, Juncus maritimus, and Eleocharis palustris for removal of de-icing salts from runoff water. Environ Sci Pollut Res 23:19634-19644

Hartzendorf T, Rolletschek H (2001) Effects of NaCl-salinity on amino acid and carbohydrate contents of Phragmites australis. Aquat Bot 69:195-208

Hasanuzzaman M, Nahar K, Alam M, Bhowmik PC, Hossain M, Rahman MM, Prasad MN, Ozturk M, Fujita M (2014) Potential use of halophytes to remediate saline soils. Biomed Res Int 2014:589341

Hootsmans MJM, Wiegman F (1998) Four helophyte species growing under salt stress: their salt of life? Aquat Bot 62:81-94. https:// doi.org/10.1016/S0304-3770(98)00085-0

Ivushkin K, Bartholomeus H, Bregt AK, Pulatov A, Kempen B, de Sousa L (2019) Global mapping of soil salinity change. Remote Sens Environ 231:111260. https://doi.org/10.1016/j.rse.2019. 111260

Jesus JM, Calheiros CSC, Castro PML, Borges MT (2014) Feasibility of Typha Latifolia for high salinity effluent treatment in constructed wetlands for integration in resource management systems. Int J Phytoremediation 16:334-346. https://doi.org/10.1080/15226 514.2013.773284

Jesus JM, Cassoni AC, Danko AS, Fiúza A, Borges M-T (2017) Role of three different plants on simultaneous salt and nutrient reduction from saline synthetic wastewater in lab-scale constructed wetlands. Sci Total Environ 579:447-455. https://doi.org/10.1016/j. scitotenv.2016.11.074

Jesus JM, Danko AS, Fiúza A, Borges MT (2015) Phytoremediation of salt-affected soils: a review of processes, applicability, and the impact of climate change. Environ Sci Pollut Res 22:6511-6525
Kaplan EL, Meier P (1958) Nonparametric estimation from incomplete observations. J Am Stat Assoc 53:457-481

Kassambara A, Kosinski M (2018) Survminer: Drawing survival curves using "ggplot2."

Khandare RV, Govindwar SP (2015) Phytoremediation of textile dyes and effluents : current scenario and future prospects. Biotechnol Adv 33:1697-1714. https://doi.org/10.1016/j.biotechadv.2015. 09.003

Krishnapillai M, Ranjan RS (2005) Evaluating the phytoremediation potential of Atriplex patula on salt sontaminated soil. Csae/Scgr $1-11$

Lim YC, Shih Y-J, Tsai K-C, Yang W-D, Chen C-W, Dong C-D (2020) Recycling dredged harbor sediment to construction materials by sintering with steel slag and waste glass: characteristics, alkali-silica reactivity and metals stability. J Environ Manage 270:110869. https://doi.org/10.1016/j.jenvman.2020.110869

Litalien A, Zeeb B (2020) Curing the earth: A review of anthropogenic soil salinization and plant-based strategies for sustainable mitigation. Sci Total Environ 698:134235. https://doi.org/10.1016/j.scito tenv.2019.134235

Lissner J, Schierup H-H (1997) Effects of salinity on the growth of Phragmites australis. Aquat Bot 55:247-260. https://doi.org/10. 1016/S0304-3770(96)01085-6

Lissner J, Schierup H-H, Comin FA, Astorga V (1999a) Effect of climate on the salt tolerance of two Phragmites australis populations. I. Growth, inorganic solutes, nitrogen relations and osmoregulation. Aquat. Bot. 17

Lissner J, Schierup H-H., Comın FA, Astorga V (1999b) Effect of climate on the salt tolerance of two Phragmites australis populations. II. Diurnal CO2 exchange and transpiration. Aquat Bot. 16

Manousaki E, Kalogerakis N (2011) Halophytes present new opportunities in phytoremediation of heavy metals and saline soils. Ind Eng Chem Res 50:656-660. https://doi.org/10.1021/ie100270x

Masciandaro G, Biase AD, Macci C, Peruzzi E, Iannelli R, Doni S (2014) Phytoremediation of dredged marine sediment: monitoring of chemical and biochemical processes contributing to sediment reclamation. J Environ Manage 134:166-174. https://doi.org/10. 1016/j.jenvman.2013.12.028

Matoh T, Matsushita N, Takahashi E (1988) Salt tolerance of the reed plant Phragmites communis. Physiol Plant 72:8-14

Mauchamp A, Mésleard F (2001) Salt tolerance in Phragmites australis populations from coastal Mediterranean marshes. Aquat Bot 70:39-52. https://doi.org/10.1016/S0304-3770(00)00140-6

McSorley K, Rutter A, Cumming R, Zeeb BA (2016a). Chloride accumulation vs chloride excretion: phytoextraction potential of three halophytic grass species growing in a salinized landfill. Sci. Total Environ 1; 572:1132-1137. https://doi.org/10.1016/j.scitotenv. 2016.08.023

McSorley K, Rutter A, Cumming R, Zeeb BA (2016b) Phytoextraction of chloride from a cement kiln dust (CKD) contaminated landfill with Phragmites australis. Waste Manag 51:111-118. https://doi. org/10.1016/j.wasman.2015.11.009

Moore GE, Burdick DM, Peter CR, Keirstead DR (2012) Belowground biomass of Phragmites australis in coastal marshes. Northeast Nat 19(4):611-626

Morteau B, Tiffault-Bouchet G, Galvez R, LeroueilS (2009) Treatment of salted road runoffs using Typha latifolia, Spergularia canadensis, and Atriplex patula: a comparison of their salt removal potential. J ASTM Intl 1-7

Padmavathiamma PK, Ahmed M, Rahman HA (2014) Phytoremediation - A sustainable approach for contaminant remediation in arid and semi-arid regions - a review. Emir J Food Agric 26:757-772. https://doi.org/10.9755/ejfa.v26i9.18202

Pavlik V (2000) Water extraction of chloride, hydroxide and other ions from hardened cement pastes. Cem Concr Res 30:895-906 
Pouladi SF, Anderson BC, Wootton B, Rozema L (2016) Evaluation of phytodesalination potential of vegetated bioreactors treating greenhouse effluent. Water 8:1-20. https://doi.org/10.3390/w8060 233

Prabakaran K, Li J, Anandkumar A, Leng Z, Zou CB, Du D (2019) Managing environmental contamination through phytoremediation by invasive plants: A review. Ecol Eng 138:28-37. https:// doi.org/10.1016/j.ecoleng.2019.07.002

Qadir M, Oster J (2002) Vegetative bioremediation of calcareous sodic soils: history, mechanisms, and evaluation. Irrig Sci 21:91-101

Qadir M, Oster JD, Schuber S, Noble AD (2007) Phytoremediation of sodic and saline-sodic soils. Adv Agron 96:197-247. https://doi. org/10.1016/S0065-2113(07)96006-X

R Core Team (2018) R: A language and environment for statistical computing

Rabhi M, Hafsi C, Lakhdar A, Hajji S, Barhoumi Z, Hamrouni MH, Abdelly C, Smaoui A (2009) Evaluation of the capacity of three halophytes to desalinize their rhizosphere as grown on saline soils under nonleaching conditions. Afr J Ecol 47:463-468. https://doi. org/10.1111/j.1365-2028.2008.00989.x

Rabhi M, Talbi O, Atia A, Abdelly C (2008) Selection of a halophyte that could be used in the bioreclamation of salt-affected soils in arid and semi-arid regions, in: Biosaline Agriculture and High Salinity Tolerance. pp. 241-246. https://doi.org/10.1007/ 978-3-7643-8554-5

Rozema ER, Gordon RJ, Zheng Y (2016) Harvesting plants in constructed wetlands to increase biomass production and $\mathrm{Na}+$ and $\mathrm{Cl}-$ removal from recycled greenhouse nutrient solution. Water Air Soil Pollut 227:136

Rozema ER, Gordon RJ, Zheng Y (2014) Plant species for the removal of $\mathrm{Na}+$ and $\mathrm{Cl}-$ from greenhouse nutrient solution. HortScience 49:1071-1075. https://doi.org/10.21273/HORTSCI.49.8.1071

RStudio Team (2016). RStudio: integrated development environment for R.

Sassine L, Khaska M, Ressouche S, Simler R, Lancelot J, Verdoux P, Le Gal La Salle C (2015) Coupling geochemical tracers and pesticides to determine recharge origins of a shallow alluvial aquifer: case study of the Vistrenque hydrogeosystem (SE France). Appl Geochem 56:11-22. https://doi.org/10.1016/j.apgeochem.2015. 02.001

Smith SG (1986) The cattails (Typha): Interspecific ecological differences and problems of identification. Lake Reserv Manag 2:357362. https://doi.org/10.1080/07438148609354657
Therneau TM, Grambsch PM (2000) Modeling survival data: extending the $\{\mathrm{C}\}$ ox model. Springer, New York

Therneau TM (2015) A Package for survival analysis in S

Turner NC, Jones MM (1980) Turgor maintenance by osmotic adjustment : a review and evaluation. In: Turner NC, Kramer PJ (eds) Adaptation of Plants to Water and High Temperatures Stress. John Wiley and Sons Inc, New York, pp 87-103

Vasquez E, Glenn E, Brown J, Guntenspergen G, Nelson S (2005) Salt tolerance underlies the cryptic invasion of North American salt marshes by an introduced haplotype of the common reed Phragmites australis (Poaceae). Mar Ecol Prog Ser 298:1-8. https://doi. org/10.3354/meps298001

Wang L, Chen L, Tsang DCW, Li J-S, Baek K, Hou D, Ding S, Poon C-S (2018) Recycling dredged sediment into fill materials, partition blocks, and paving blocks: Technical and economic assessment. J Clean Prod 199:69-76. https://doi.org/10.1016/j.jclepro. 2018.07.165

White P, Broadley MR (2001) Chloride in soils and its uptake and movement within the plant: a review. Ann Bot 88:967-988. https://doi.org/10.1006/anbo.2001.1540

Wickham H (2016) ggplot2: Elegant graphics for data analysis. Springer-Verlag, New York

Wu GQ, Jiao Q, Shui QZ (2016) Effect of salinity on seed germination, seedling growth, and inorganic and organic solutes accumulation in sunflower (Helianthus annuus L.). Plant Soil Environ. 61:220-226

Yensen NP, Biel KY (2006). Soil remediation via salt-conduction and the hypotheses of halosynthesis and photoprotection, in: Ecophysiology of High Salinity Tolerant Plants. Springer, pp. 313-344.

Yu J, Wang X, Ning K, Li Y, Wu H, Fu Y, Zhou D, Guan B, Lin Q (2012) Effects of salinity and water depth on germination of Phragmites australis in coastal wetland of the yellow river delta. CLEAN - Soil Air Water 40:1154-1158. https://doi.org/10.1002/ clen.201100743

Zeng L, Shannon MC, Grieve CM (2002) Evaluation of salt tolerance in rice genotypes by multiple agronomic parameters. Euphytica 127:235-245

Publisher's note Springer Nature remains neutral with regard to jurisdictional claims in published maps and institutional affiliations.

\section{Authors and Affiliations}

\section{Emmanuel Delattre ${ }^{1} \cdot$ Isabelle Techer ${ }^{1}$ (D) $\cdot$ Benjamin Reneaud ${ }^{1} \cdot$ Patrick Verdoux $^{1} \cdot$ Isabelle Laffont-Schwob $^{2}$. Philippe Prohin ${ }^{3}$}

Emmanuel Delattre

delattreemmanuel@orange.fr

Benjamin Reneaud

benjamin.reneaud@unimes.fr

Patrick Verdoux

patrick.verdoux@unimes.fr

Isabelle Laffont-Schwob

isabelle.schwob@univ-amu.fr
Philippe Prohin

nymphea30@orange.fr

1 UPR CHROME, Université de Nîmes, rue du Dr. Georges Salan, 30021 Nimes, France

2 Aix Marseille Univ, IRD, LPED, Marseille, France

3 Nymphéa Distribution, 30740 Le Cailar, France 